Abstract: $\quad 236$ words

Manuscript text: 2810 words

\title{
Endogenous and exogenous testosterone and the risk of prostate cancer and increased prostate specific antigen (PSA): a meta-analysis
}

Boyle P. ${ }^{1,2,7}$, Koechlin A. ${ }^{1,2}$, Bota M. ${ }^{1,2}$, d'Onofrio A. ${ }^{2}$, Zaridze D.G. ${ }^{3}$, Perrin P. ${ }^{4}$, Fitzpatrick J. ${ }^{5,}$, Burnett A.L. ${ }^{6}$ and Boniol M. ${ }^{1,2}$

1. Strathclyde Institute of Global Public Health at iPRI, Espace Européen d'Ecully, Bâtiment G, Allée Claude Debussy, 69130 Ecully Lyon ouest, France

2. International Prevention Research Institute, 95 cours Lafayette, 69006 Lyon, France

3. Director, Institute of Carcinogenesis, Kashiroe Sh. 24, Moscow 115478, Russian Federation

4. Urologie, Centre Hospitalier Lyon Sud, 69495 Pierre-Bénite, France

5. Irish Cancer Society, 43/45 Northumberland Rd, Dublin 4, Ireland

6. Patrick C. Walsh Distinguished Professor of Urology, Cellular and Molecular Medicine, Johns Hopkins Medicine, 600 North Wolfe Street, Marburg 407, Baltimore, Maryland 21287, United States of America

7. Address for correspondence: Professor Peter Boyle, Strathclyde Institute of Public Health at iPRI, Espace Européen d'Ecully, Bâtiment G, Allée Claude Debussy, 69130 Ecully Lyon ouest, France. Telephone +33 (0)4 721711 84; email peter.boyle@strath.ac.uk

*Tragically, Professor John Fitzpatrick passed away between the completion of the full Technical Report and the completion of the manuscript. 


\section{Abstract}

Objective: To review and quantify the association between endogenous and exogenous testosterone and prostate specific antigen (PSA) and prostate cancer.

Methods: Literature searches were performed following the PRISMA guidelines. Prospective cohort studies that reported data on the associations between endogenous testosterone and prostate cancer, and placebo controlled randomised trials of testosterone replacement therapy (TRT) that reported data on PSA and/or prostate cancer cases were retained. Metaanalyses were performed using random-effects models with tests for publication bias and heterogeneity.

Results: Twenty estimates were included in a meta-analysis which produced a summary relative risk of prostate cancer for an increase of $5 \mathrm{nmol} / \mathrm{L}$ of testosterone of $0.99(95 \% \mathrm{Cl}$ $(0.96,1.02))$ without heterogeneity $\left(I^{2}=0 \%\right)$. Based on 26 trials, the overall difference in PSA levels following onset of use of TRT was $0.10 \mathrm{ng} / \mathrm{mL}(-0.28,0.48)$. Results were similar when conducting heterogeneity analyses by mode of administration, region, age at baseline, baseline testosterone, trial duration, type of patients and type of testosterone replacement therapy. The summary relative risk of prostate cancer as an adverse effect from 11 TRT trials was $0.87(0.30 ; 2.50)$. Results were consistent across studies.

Conclusions: Prostate cancer appears to be unrelated to endogenous testosterone levels. Testosterone replacement therapy for symptomatic hypogonadism does not appear to increase PSA levels nor the risk of prostate cancer development. The current data are reassuring although some care is essential until multiple studies with longer follow-up are available.

Keywords: prostate cancer, testosterone, PSA, meta-analysis 


\section{Introduction}

Testosterone is important for normal growth, development and maintenance of the prostate gland. Testosterone deficiency in aging men has become a topic of increasing interest and debate worldwide. Cross-sectional and longitudinal data indicate that testosterone levels are reduced progressively with age and that a significant percentage of men aged over 60 years have serum testosterone levels that are below the lower limits of young adult men aged 2030 years [1-3]. Late onset hypogonadism ( $\mathrm{LOH})$ is a clinical and biochemical syndrome associated with advancing age and characterized by a deficiency in serum testosterone levels, among other signs and symptoms [4, 5]. Late onset hypogonadism may result in significant detriment to quality of life and adversely affect the function of multiple organ systems. Therefore, there has been a growing awareness of the potential health benefits of testosterone therapy for men with testosterone deficiency, including improved sexual desire and performance, improved mood, increased muscle mass and strength, decreased fat mass and improved bone mineral density [6].

More than 60 years ago, Huggins demonstrated that suppression of testosterone levels caused regression of prostate cancer, and it is now commonplace for men with metastatic prostate cancer to undergo treatment designed to lower testosterone levels [7]. Many urologists are concerned that testosterone replacement therapy may accelerate prostate growth not only in benign disease but also in cancer. If lowering testosterone causes prostate cancer to regress in men, does elevating testosterone cause prostate cancer to appear?

Prostate cancer is the second most common cancer in men and a high proportion of men harbour microscopic foci of prostate cancer [8]. It has been hypothesized that sex hormones and androgens in particular might be involved in prostate cancer carcinogenesis. Zaridze and co-workers concluded from qualitative analysis that there was little, if any, association between serum levels of testosterone and the risk of prostate cancer [9]. A collaborative analysis of 18 prospective studies on endogenous sex hormones and prostate cancer conducted in 2008 found no associations between the risk of prostate cancer and serum concentrations of testosterone, or other sex hormones [10]. Additionally, an increase in exogenous testosterone replacement therapies has been encouraged by media attention and marketing of new transdermal formulations (patches or gels) for the treatment of $\mathrm{LOH}$. Several systematic reviews discussed about the benefits and risks of testosterone treatment [11-13], and several meta-analyses tried to quantify these risks [14-16].

This review aims at evaluating the potential relationship between testosterone and prostate cancer, and to synthesise all available data regarding the impact of testosterone replacement therapy (TRT) on changes in Prostate Specific Antigen (PSA) levels and on the risk of development of prostate cancer. Two approaches have been employed, separately for endogenous and exogenous testosterone. A meta-analysis of long-term observational data has been retained for quantifying the relationship between endogenous levels of testosterone and prostate cancer. A meta-analysis of short-term placebo-controlled randomised trials of testosterone supplementation and their adverse effects was done in order to test the hypothesis of a rapid acceleration of prostatic cancer development with the use of exogenous testosterone.

\section{Methods}


A systematic literature search and quantitative analysis was planned, conducted and reported following PRISMA guidelines [17]. Published reports were obtained from the Cochrane library and PUBMED. Other sources were found in the reference lists of the retrieved articles and preceding reviews on the topic. There was no restriction on geographical location of studies, but only articles published in English were considered. Articles were first screened by title and abstract. Then, full copies of the potentially relevant articles were retrieved and read by at least two co-authors. Data were then extracted in a predefined database by one author, and double-checked by the statistician who performed the analyses.

\section{Endogenous testosterone}

The Endogenous Hormones and Prostate Cancer Collaborative Group (EHPCCG) published a pooled analysis of 18 prospective studies [10]. Original articles from each study identified by the EHPCCG, including those not included in the pooled analysis, were retrieved. Then, a literature search was performed in May 2015 for the period 2007-2015 in order to collect articles published after the EHPCCG pooled analysis.

Only prospective studies including cohort studies, nested case-control studies, case-cohort studies and control arms of randomized controlled trials were eligible. Articles had to report risk estimates for prostate cancer according to baseline serum testosterone levels. The list of keywords for literature search is reported in supplementary figure (Figure S1). A doseresponse meta-analysis was conducted for the calculation of the summary relative risk (SRR) corresponding to an increase of $5 \mathrm{nmol} / \mathrm{L}$ of baseline testosterone [18]. A change of $5 \mathrm{nmol} / \mathrm{L}$ corresponds broadly to the average difference between tertiles of population in the studies included in the present meta-analysis. Heterogeneity analyses were performed in order to investigate potential sources of variation between studies: by region (USA, Europe), age at baseline (cut-off 65 years) and follow-up duration (cut-off 10 years).

The following variables were extracted: first author name and year of publication, country, baseline age, baseline testosterone ( $\mathrm{nmol} / \mathrm{L})$, follow-up duration and for each quantile of testosterone, mean or median testosterone ( $\mathrm{nmol} / \mathrm{L})$, number of subjects, person-years, relative risk estimate and $95 \%$ confidence interval $(\mathrm{Cl})$.

\section{Exogenous testosterone}

The meta-analyses focused on the potential associations between use of TRT and 1) changes in PSA level and 2) incidence of prostate cancer. Placebo-controlled, randomized trials reporting statistics on these two outcomes were eligible for the meta-analysis. The included outcome for change in PSA level could have been PSA level at baseline and end of study or change in PSA level during the study. For incidence of prostate cancer, it could have been number of prostate cancer occurring in each treatment arm, incidence rate, or oddsratio comparing treatment arm to control group.

The following variables were extracted: first author name and year of publication, country, baseline age, baseline testosterone ( $\mathrm{nmol} / \mathrm{L}$ ), follow-up duration, type of subjects (healthy or other), drug name and dose, mode of administration, number of participants by group, PSA level related data and number of prostate cancer cases by group. 
Data were abstracted on change in PSA level and its corresponding standard deviation. For studies that reported only baseline and end of study PSA with corresponding standard deviation, the variance of the average difference was estimated with the variance of PSA baseline and PSA end of study using a correlation factor to account for auto-correlation. This correction factor was calculated using data from the Prostate, Lung, Colorectal and Ovarian (PLCO) cancer screening trial [19]. Detailed information about this correction factor are available in the Supplementary methods.

Heterogeneity analyses were undertaken by region (USA, Europe), mode of administration (transdermal, intramuscular, oral), type of patients (healthy subjects, subjects with preexisting comorbidities), age at baseline (cut-off 65 years), trial duration (cut-off one year) and baseline testosterone (cut-off $11 \mathrm{nmol} / \mathrm{L}$ ). This cut-off was chosen because it was the $5^{\text {th }}$ percentile of the serum testosterone distribution of healthy men aged 35-44 [20]. An analysis by dose of testosterone could not be undertaken because of differences in modes and frequencies of administrations.

\section{Prostate cancer}

Following Cochrane review guidelines [21], studies reporting zero cases in both intervention and control arms were excluded. Since these studies deal with rare events, odds ratios and corresponding $95 \% \mathrm{Cl}$ were calculated applying a correction of 0.5 to all entries. The same heterogeneity analyses as for the TRT and PSA were conducted.

\section{Meta-analysis}

Meta-analyses were undertaken with restricted maximum likelihood (REML) random effects models [22]. The $95 \%$ confidence intervals of summary estimates were calculated using a tdistribution.

To summarize incidence of prostate cancer from TRT trials, because of very low event rates, the Mantel-Haenszel method was used [23, 24].

Heterogeneity across studies was evaluated by the Cochran's Q statistic and with Higgins' ${ }^{2}$ [25]. Publication bias was investigated using the funnel plot and Macaskill test [26], Begg test [27], and Egger test [28]. The meta-analyses were carried out in programming language $R$ (version 3.0.0, GNU General Public License, 2013) and package metafor [29]. In addition to the heterogeneity analyses described above, sensitivity analyses, excluding one study at a time, were performed in order to evaluate the influence of individual studies on the overall result (leave-one-out). In sensitivity analysis, the association between endogenous testosterone and prostate cancer was also computed as a high versus low meta-analysis comparing the risk in the highest quantile of PSA to the lowest quantile of PSA.

\section{Results}




\section{Endogenous testosterone levels and prostate cancer}

The literature search yielded 151 articles. After title review, 27 articles were selected for abstract reading. Twenty studies reporting risk of prostate cancer for different levels of PSA were identified (Supplementary figure 1). Two studies provided data on testosterone levels to EHPCCG, but did not publish these data independently and could not be included in the present work [30, 31]. Data from the Janus databank were used twice in the pooled analysis, but the two datasets were independent and were considered as two separate studies [32, 33]. Stattin and colleagues published data from three cohorts and risk estimates were included separately [32]. Studies included in the meta-analysis included 5,623 prostate cancer cases and 14,604 controls. Average follow-up was 10 years (Table 1).

The summary relative risk (SRR) for an increase of $5 \mathrm{nmol} / \mathrm{L}$ of serum testosterone was 0.99 $(95 \% \mathrm{Cl}(0.96 ; 1.02))$. There was no evidence of heterogeneity $\left(\mathrm{I}^{2}=0 \%\right)$ nor of publication bias $\left(p_{\text {Begg }}=0.87 ; p_{\text {Egger }}=0.17 ; p_{\text {Macaskill }}=0.69\right)$ (Figure 1$)$. In addition, visual inspection of the funnel plot did not suggest publication bias. The leave-one-out analysis showed that no study taken individually had a big influence on the SRR. The heterogeneity analyses showed that results were consistent by region, age at baseline and duration of follow-up. A sensitivity analysis based on high versus low serum testosterone approach yielded similar results: $\mathrm{SRR}=0.98(95 \% \mathrm{Cl}(0.88 ; 1.09))$ (Table 3).

\section{Testosterone supplementation and increase in PSA levels}

Twenty-seven placebo-controlled trials were included in the quantitative analysis of testosterone supplementation and its adverse effects. Twenty-seven studies reported data on PSA levels, and 11 reported data on incidence of prostate cancer (Supplementary Figure 2). This involved a total of 2213 subjects in the intervention groups, and 1456 subjects in the placebo control groups. The median trial duration was 196 days. In 13 trials, TRT was administered transdermally (patch or gel), in nine trials intramuscularly, and in four trials orally. Thirteen studies were conducted in the United States, 10 in Europe, two in Asia and one in Australia. Fifteen trials were carried out in healthy subjects and 11 in patients with preexisting comorbidities such as diabetes mellitus or metabolic syndrome (Table 2).

A total of 27 studies produced unique estimates of the change in PSA levels after onset of use of testosterone replacement therapy. One of them did not provide variability data and was excluded from the main analysis [34]. The summary difference (SES) in PSA levels was found to be $\mathrm{SES}=0.10 \mathrm{ng} / \mathrm{mL}(95 \% \mathrm{Cl}(-0.28 ; 0.48)$; (figure 2). There was no evidence of heterogeneity $\left(I^{2}=0 \%\right)$. Tests of publication bias produced conflicting results: while visual inspection of the funnel plot did not suggest publication bias and while there was no evidence of publication bias from the Begg test $\left(p_{\text {Begg }}=0.88\right)$ and the Macaskill test $\left(p_{\text {Macaskill }}=0.52\right)$, the Egger test was statistically significant $\left(p_{\text {Egger }}=0.01\right)$. In a sensitivity analysis, the study with no measure of dispersion was added, assuming a standard deviation of 1 in intervention and control arms; it did not modify the SES: $0.10 \mathrm{ng} / \mathrm{mL}(95 \% \mathrm{Cl}(-0.27 ; 0.48))$.

Heterogeneity analyses revealed that the increase in PSA levels following testosterone supplementation were slightly higher among Americans (SES $=0.34 \mathrm{ng} / \mathrm{ml}$ ) than in Europeans (SES $=0.09 \mathrm{ng} / \mathrm{ml}$ ); in older subjects (SES for $\geq 65$ years $=0.30 \mathrm{ng} / \mathrm{ml} \mathrm{vs} .0 .11$ $\mathrm{ng} / \mathrm{ml}$ for under 65 years at baseline) and among subjects with high levels of testosterone 
(SES $=0.25 \mathrm{ng} / \mathrm{ml}$ for baseline testosterone $>11 \mathrm{ng} / \mathrm{mL}$ vs. $0.07 \mathrm{ng} / \mathrm{ml}$ for others). However, these differences were small and did not reach statistical significance. TRT had a similar effect of PSA levels in healthy subjects and others. Duration of the trial had no influence on the results. There were not enough studies in the analysis by subtype of testosterone to draw conclusions (Table 3).

\section{Testosterone supplementation and risk of prostate cancer}

A total of 11 studies produced unique estimates of the risk of prostate cancer diagnosis associated following the use of testosterone replacement therapy (Table 2). The Summary Odds Ratio (SOR) was $0.87(95 \% \mathrm{Cl}(0.30 ; 2.50))$ based on 20 prostate cancer cases. There was no evidence of heterogeneity $\left(I^{2}=0 \%\right)$ nor publication bias $\left(p_{\text {Begg }}=0.82, p_{\text {Egger }}=0.26\right.$, $p_{\text {Macaskill }}=0.70$ (Figure 3). From the leave-one-out analysis, no study had a big impact on the SOR. In a sensitivity analysis, prostate cancer cases diagnosed during open-label extensions of studies were included. Three new cases of prostate cancer and two additional studies were included in this analysis [34, 35]; these did not modify the results: SOR $=0.84(95 \% \mathrm{Cl}$ $(0.31 ; 2.25))$.

Results of heterogeneity analyses should be interpreted with caution because of the low number of studies included in each analysis, resulting in poor statistical power. None of the subgroup analysis showed a statistically significant increased risk of prostate cancer (Table 3).

\section{Discussion}

\section{Endogenous Testosterone}

Serum androgens in general and testosterone in particular have been widely studied in relationship with prostate cancer development as they are potential risk factors for this disease. Results of individual studies often lacked of statistical power and were sometimes inconsistent with each other. In 2008, the EHPCCG conducted a large pooled analysis in order to summarize the existing evidence on this topic [10]. No association was found between levels of sex hormones, including testosterone, and incidence of prostate cancer.

The present work included four new studies compared to the earlier pooled analysis. In addition, this meta-analysis used a dose-response modelling instead of using a high vs. low approach. Our results confirmed those of the EHPCCG pooled analysis, i.e. high serum testosterone levels were not associated with increased risk of prostate cancer in prospective observational studies. Heterogeneity analyses showed that results were similar by region, age at baseline and duration of follow-up.

\section{Exogenous testosterone}

Testosterone supplementation for the treatment of hypogonadism is controversial. With the direct-to-consumer advertising and very rapid increase in testosterone prescription, some authors suggested that hypogonadism was largely disease mongering [36]. There is some evidence to suggest improved libido, muscle mass or mood [6], but also several concerns about the possible stimulation of prostate growth. 
There was no evidence of increased PSA levels after testosterone supplementation from an analysis of data from 27 placebo controlled, randomized trials. No major source of heterogeneity was identified. From the 11 trials reporting prostate cancer cases, the metaanalysis found no evidence of an increased risk of prostate cancer associated with testosterone replacement therapy.

A limitation to this analysis is the relative short duration of the trials with most of the trials lasting less than one year. This was an issue mainly for the prostate cancer analysis. With such a short follow-up, few prostate cancers cases were reported, resulting in low statistical power. The analysis restricted to studies with a follow-up greater than one year did not show an increase risk of prostate cancer nor a change in PSA level. A possible publication bias might be taken into consideration, as more than half of the articles that were found otherwise eligible, were excluded because they did not report enough data.

These results were consistent with data reported in previous meta-analyses. Cui and colleagues [14], using data from eight trials, concluded that TRT did not promote prostate cancer development; furthermore, using data from 12 trials, they found no difference in abnormal PSA levels between treated and un-treated patients. Fernandez-Balsells and colleagues reported the SRR for prostate cancer to be $0.79(95 \% \mathrm{Cl}(0.28 ; 2.28))$, based on five studies [16]. Calof and colleagues concluded that the number of "prostate events" (biopsies, cancers, increase in IPSS $>4$, PSA $>4 \mathrm{ng} / \mathrm{mL}$ or PSA increment $>1.5 \mathrm{ng} / \mathrm{mL}$ during treatment, and acute urinary retention) was higher in the intervention group than in the placebo group (pooled OR $1.78(95 \% \mathrm{Cl} 1.07 ; 2.95)$ ). However, the risk of "prostate events" was essentially limited to prostate biopsies (pooled OR 1.87), and prostate cancer alone was not significantly higher (pooled OR 1.09 (95\% Cl 0.48; 2.49)) [15].

It could also be hypothesised that the potential impact of testosterone therapy on prostate growth be limited to older men, or individuals with initially low level of testosterone, or vary according to route of administration. However, none of the heterogeneity analysis confirmed these hypotheses.

\section{Conclusions}

The earlier work of the EHPCCG showed no association between serum testosterone levels and risk of prostate cancer [10]. More recent studies confirmed this lack of association; no individual study found any increased or decreased risk of prostate cancer among men with high levels of testosterone compared to lower levels. Meta-analysis showed no association between testosterone levels and prostate cancer risk. Prostate cancer development appears unrelated to endogenous serum testosterone levels.

The available data do not support an increase in the risk of prostate cancer associated with testosterone replacement therapy nor do they support a change in PSA levels when testosterone replacement therapy is used. Testosterone replacement therapy for symptomatic hypogonadism does not appear to increase PSA levels nor the risk of prostate cancer development. The current data are reassuring although some care is still essential until multiple studies with longer follow-up are available. 


\section{Acknowledgments}

Conflict of Interest Statement: The authors declare that they have no relevant financial interests including stock ownership, consultant contracts, members of Advisory Boards or speakers bureau for any pharmaceutical company in the field of Urology.

Funding Support: The study was partially funded by an unrestricted research grant from Repros Therapeutics Inc (The Woodlands, Texas) and the International Prevention Research Institute. The study was designed, conducted and reported in full independence from the external sponsor (Repros Therapeutics Inc). No author received any personal benefit, in terms of honorarium, from this research grant.

Acknowledgements: The authors thank Kim Coppens and Faustine Valentini for their assistance with the literature searches and their preparation of the manuscript for submission. 


\section{References}

[1] Harman SM, Metter EJ, Tobin JD, Pearson J, Blackman MR, Baltimore Longitudinal Study of A. Longitudinal effects of aging on serum total and free testosterone levels in healthy men. Baltimore Longitudinal Study of Aging. J Clin Endocrinol Metab. 2001 Feb: 86:724-31

[2] Araujo $A B$, Esche GR, Kupelian V, et al. Prevalence of symptomatic androgen deficiency in men. J Clin Endocrinol Metab. 2007 Nov: 92:4241-7

[3] Wu FC, Tajar A, Pye SR, et al. Hypothalamic-pituitary-testicular axis disruptions in older men are differentially linked to age and modifiable risk factors: the European Male Aging Study. J Clin Endocrinol Metab. 2008 Jul: 93:2737-45

[4] Morales A, Schulman CC, Tostain J, F CWW. Testosterone Deficiency Syndrome (TDS) needs to be named appropriately--the importance of accurate terminology. Eur Urol. 2006 Sep: 50:407-9

[5] Wang $C$, Nieschlag $E$, Swerdloff $R$, et al. Investigation, treatment, and monitoring of lateonset hypogonadism in males: ISA, ISSAM, EAU, EAA, and ASA recommendations. Eur Urol. 2009 Jan: 55:121-30

[6] Wang C, Cunningham G, Dobs A, et al. Long-term testosterone gel (AndroGel) treatment maintains beneficial effects on sexual function and mood, lean and fat mass, and bone mineral density in hypogonadal men. J Clin Endocrinol Metab. 2004 May: 89:2085-98

[7] Huggins C, Stevens REJ, Hodges C. Studies on prostatic cancer. II. The effects of castration on advanced carcinoma of the prostate gland. Arch Surg. 1941: 43:209-23

[8] Sakr WA, Haas GP, Cassin BF, Pontes JE, Crissman JD. The frequency of carcinoma and intraepithelial neoplasia of the prostate in young male patients. J Urol. 1993 Aug: 150:379-85

[9] Zaridze DG, Boyle P, Smans M. International trends in prostatic cancer. Int J Cancer. 1984 Feb 15: 33:223-30

[10] Endogenous Hormones and Prostate Cancer Collaborative Group, Roddam AW, Allen NE, Appleby P, Key TJ. Endogenous sex hormones and prostate cancer: a collaborative analysis of 18 prospective studies. J Natl Cancer Inst. 2008 Feb 6: 100:170-83

[11] Rhoden EL, Morgentaler A. Risks of testosterone-replacement therapy and recommendations for monitoring. N Engl J Med. 2004 Jan 29: 350:482-92

[12] Atan A, Tuncel A, Yesil S, Balbay D. Serum testosterone level, testosterone replacement treatment, and prostate cancer. Adv Urol. 2013: 2013:275945

[13] Shabsigh R, Crawford ED, Nehra A, Slawin KM. Testosterone therapy in hypogonadal men and potential prostate cancer risk: a systematic review. Int J Impot Res. 2009 Jan-Feb: 21:9-23

[14] Cui Y, Zong H, Yan H, Zhang Y. The effect of testosterone replacement therapy on prostate cancer: a systematic review and meta-analysis. Prostate Cancer Prostatic Dis. 2014 Jan 21:

[15] Calof OM, Singh AB, Lee ML, et al. Adverse events associated with testosterone replacement in middle-aged and older men: a meta-analysis of randomized, placebo-controlled trials. J Gerontol A Biol Sci Med Sci. 2005 Nov: 60:1451-7

[16] Fernandez-Balsells MM, Murad MH, Lane $M$, et al. Clinical review 1: Adverse effects of testosterone therapy in adult men: a systematic review and meta-analysis. J Clin Endocrinol Metab. 2010 Jun: 95:2560-75

[17] Moher D, Liberati A, Tetzlaff J, Altman DG, Group P. Preferred reporting items for systematic reviews and meta-analyses: the PRISMA statement. BMJ. 2009: 339:b2535

[18] Greenland S, Longnecker MP. Methods for trend estimation from summarized dose-response data, with applications to meta-analysis. Am J Epidemiol. 1992 Jun 1: 135:1301-9

[19] Andriole GL, Crawford ED, Grubb RL, 3rd, et al. Prostate cancer screening in the randomized Prostate, Lung, Colorectal, and Ovarian Cancer Screening Trial: mortality results after 13 years of follow-up. J Natl Cancer Inst. 2012 Jan 18: 104:125-32

[20] Vermeulen A. Declining Androgens with Age: An Overview. In Oddens BJ, Vermeulen A eds, Androgens and the Aging Male, Vol. 3-14. New York, NY Parthenon Publishing Group, 1996

[21] Higgins JPT, Green S. Cochrane Handbook for Systematic Reviews of Interventions Version 5.0.2 [updated September 2009]: The Cochrane Collaboration, 2009 
[22] van Houwelingen HC, Arends LR, Stijnen T. Advanced methods in meta-analysis: multivariate approach and meta-regression. Stat Med. 2002 Feb 28: 21:589-624

[23] Greenland S, Robins JM. Estimation of a common effect parameter from sparse follow-up data. Biometrics. 1985 Mar: 41:55-68

[24] Mantel N, Haenszel W. Statistical aspects of the analysis of data from retrospective studies of disease. J Natl Cancer Inst. 1959 Apr: 22:719-48

[25] Higgins JP, Thompson SG. Quantifying heterogeneity in a meta-analysis. Stat Med. 2002 Jun 15: 21:1539-58

[26] Macaskill P, Walter SD, Irwig L. A comparison of methods to detect publication bias in metaanalysis. Statist Med. 2001: 20:641-54

[27] Begg CB, Mazumdar M. Operating characteristics of a rank correlation test for publication bias. Biometrics. 1994 Dec: 50:1088-101

[28] Egger M, Davey Smith G, Schneider M, Minder C. Bias in meta-analysis detected by a simple, graphical test. BMJ. 1997 Sep 13: 315:629-34

[29] Viechtbauer W. Conducting meta-analyses in R with the metafor package. J Stat Softw. 2010: 36:1-48

[30] Oliver SE, Gunnell D, Donovan J, et al. Screen-detected prostate cancer and the insulin-like growth factor axis: results of a population-based case-control study. Int J Cancer. 2004 Mar 1: 108:887-92

[31] Corder EH, Friedman GD, Vogelman JH, Orentreich N. Seasonal variation in vitamin D, vitamin D-binding protein, and dehydroepiandrosterone: risk of prostate cancer in black and white men. Cancer Epidemiol Biomarkers Prev. 1995 Sep: 4:655-9

[32] Stattin P, Lumme S, Tenkanen L, et al. High levels of circulating testosterone are not associated with increased prostate cancer risk: a pooled prospective study. Int J Cancer. 2004 Jan 20: 108:418-24

[33] Vatten LJ, Ursin G, Ross RK, et al. Androgens in serum and the risk of prostate cancer: a nested case-control study from the Janus serum bank in Norway. Cancer Epidemiol Biomarkers Prev. 1997 Nov: 6:967-9

[34] Morgentaler A, Benesh JA, Denes BS, Kan-Dobrosky N, Harb D, Miller MG. Factors influencing prostate-specific antigen response among men treated with testosterone therapy for 6 months. J Sex Med. 2014 Nov: 11:2818-25

[35] Kaufman JM, Miller MG, Garwin JL, Fitzpatrick S, McWhirter C, Brennan JJ. Efficacy and safety study of 1.62\% testosterone gel for the treatment of hypogonadal men. J Sex Med. 2011 Jul: 8:207989

[36] Perls T, Handelsman DJ. Disease mongering of age-associated declines in testosterone and growth hormone levels. J Am Geriatr Soc. 2015 Apr: 63:809-11

[37] Barrett-Connor E, Garland C, McPhillips JB, Khaw KT, Wingard DL. A prospective, populationbased study of androstenedione, estrogens, and prostatic cancer. Cancer Res. 1990 Jan 1: 50:169-73

[38] Chen C, Weiss NS, Stanczyk FZ, et al. Endogenous Sex Hormones and Prostate Cancer Risk: A Case-Control Study Nested within the Carotene and Retinol Efficacy Trial. Cancer Epidemiol Biomarkers Prev. 2003: 12:1410-6

[39] Daniels NA, Nielson CM, Hoffman AR, Bauer DC, Osteoporotic Fractures In Men Study G. Sex hormones and the risk of incident prostate cancer. Urology. 2010 Nov: 76:1034-40

[40] Dorgan JF, Albanes D, Virtamo J, et al. Relationships of serum androgens and estrogens to prostate cancer risk: results from a prospective study in Finland. Cancer Epidemiol Biomarkers Prev. 1998 Dec: 7:1069-74

[41] Gann PH, Hennekens CH, Ma J, Longcope C, Stampfer MJ. Prospective study of sex hormone levels and risk of prostate cancer. J Natl Cancer Inst. 1996 Aug 21: 88:1118-26

[42] Gill JK, Wilkens LR, Pollak MN, Stanczyk FZ, Kolonel LN. Androgens, growth factors, and risk of prostate cancer: the Multiethnic Cohort. Prostate. 2010 Jun 1: 70:906-15

[43] Heikkila R, Aho K, Heliovaara M, et al. Serum testosterone and sex hormone-binding globulin concentrations and the risk of prostate carcinoma: a longitudinal study. Cancer. 1999 Jul 15: 86:312-5 
[44] Hsing AW, Comstock GW. Serological precursors of cancer: serum hormones and risk of subsequent prostate cancer. Cancer Epidemiol Biomarkers Prev. 1993 Jan-Feb: 2:27-32

[45] Muller RL, Gerber L, Moreira DM, Andriole G, Castro-Santamaria R, Freedland SJ. Serum testosterone and dihydrotestosterone and prostate cancer risk in the placebo arm of the Reduction by Dutasteride of Prostate Cancer Events trial. Eur Urol. 2012 Nov: 62:757-64

[46] Nomura AM, Stemmermann GN, Chyou PH, Henderson BE, Stanczyk FZ. Serum androgens and prostate cancer. Cancer Epidemiol Biomarkers Prev. 1996 Aug: 5:621-5

[47] Ozasa K, Nakao M, Watanabe $Y$, et al. Serum phytoestrogens and prostate cancer risk in a nested case-control study among Japanese men. Cancer Sci. 2004: 95:65-71

[48] Parsons JK, Carter HB, Platz EA, Wright EJ, Landis P, Metter EJ. Serum testosterone and the risk of prostate cancer: potential implications for testosterone therapy. Cancer Epidemiol Biomarkers Prev. 2005 Sep: 14:2257-60

[49] Platz EA, Leitzmann MF, Rifai N, et al. Sex steroid hormones and the androgen receptor gene CAG repeat and subsequent risk of prostate cancer in the prostate-specific antigen era. Cancer Epidemiol Biomarkers Prev. 2005 May: 14:1262-9

[50] Severi G, Morris HA, MacInnis RJ, et al. Circulating steroid hormones and the risk of prostate cancer. Cancer Epidemiol Biomarkers Prev. 2006 Jan: 15:86-91

[51] Travis RC, Key TJ, Allen NE, et al. Serum androgens and prostate cancer among 643 cases and 643 controls in the European Prospective Investigation into Cancer and Nutrition. Int J Cancer. 2007 Sep 15: 121:1331-8

[52] Weiss JM, Huang WY, Rinaldi S, et al. Endogenous sex hormones and the risk of prostate cancer: a prospective study. Int J Cancer. 2008 May 15: 122:2345-50

[53] Amory JK, Watts NB, Easley KA, et al. Exogenous testosterone or testosterone with finasteride increases bone mineral density in older men with low serum testosterone. J Clin Endocrinol Metab. 2004 Feb: 89:503-10

[54] Aversa A, Bruzziches R, Francomano D, et al. Effects of testosterone undecanoate on cardiovascular risk factors and atherosclerosis in middle-aged men with late-onset hypogonadism and metabolic syndrome: results from a 24-month, randomized, double-blind, placebo-controlled study. J Sex Med. 2010 Oct: 7:3495-503

[55] Basaria S, Coviello AD, Travison TG, et al. Adverse events associated with testosterone administration. N Engl J Med. 2010 Jul 8: 363:109-22

[56] Behre HM, Tammela TL, Arver S, et al. A randomized, double-blind, placebo-controlled trial of testosterone gel on body composition and health-related quality-of-life in men with hypogonadal to low-normal levels of serum testosterone and symptoms of androgen deficiency over 6 months with 12 months open-label follow-up. Aging Male. 2012 Dec: 15:198-207

[57] Bhasin S, Storer TW, Asbel-Sethi N, et al. Effects of testosterone replacement with a nongenital, transdermal system, Androderm, in human immunodeficiency virus-infected men with low testosterone levels. J Clin Endocrinol Metab. 1998 Sep: 83:3155-62

[58] Caminiti G, Volterrani M, lellamo F, et al. Effect of long-acting testosterone treatment on functional exercise capacity, skeletal muscle performance, insulin resistance, and baroreflex sensitivity in elderly patients with chronic heart failure a double-blind, placebo-controlled, randomized study. J Am Coll Cardiol. 2009 Sep 1: 54:919-27

[59] Chiang HS, Cho SL, Lin YC, Hwang TI. Testosterone gel monotherapy improves sexual function of hypogonadal men mainly through restoring erection: evaluation by IIEF score. Urology. 2009 Apr: 73:762-6

[60] Emmelot-Vonk MH, Verhaar HJ, Nakhai Pour HR, et al. Effect of testosterone supplementation on functional mobility, cognition, and other parameters in older men: a randomized controlled trial. JAMA. 2008 Jan 2: 299:39-52

[61] Ferrando AA, Sheffield-Moore M, Yeckel CW, et al. Testosterone administration to older men improves muscle function: molecular and physiological mechanisms. Am J Physiol Endocrinol Metab. 2002 Mar: 282:E601-7 
[62] Hackett G, Cole N, Bhartia M, Kennedy D, Raju J, Wilkinson P. Testosterone replacement therapy with long-acting testosterone undecanoate improves sexual function and quality-of-life parameters vs. placebo in a population of men with type 2 diabetes. J Sex Med. 2013 Jun: 10:1612-27 [63] Hildreth KL, Barry DW, Moreau KL, et al. Effects of testosterone and progressive resistance exercise in healthy, highly functioning older men with low-normal testosterone levels. J Clin Endocrinol Metab. 2013 May: 98:1891-900

[64] Holmang S, Marin P, Lindstedt G, Hedelin H. Effect of long-term oral testosterone undecanoate treatment on prostate volume and serum prostate-specific antigen concentration in eugonadal middle-aged men. Prostate. 1993: 23:99-106

[65] Jones H, Arver S, Behre HM, et al. Testosterone Replacement in Hypogonadal Men With Type 2 Diabetes and/or Metabolic Syndrome (the TIMES2 Study). Diabetes Care. 2011: 34:828-37

[66] Kalinchenko SY, Tishova YA, Mskhalaya GJ, Gooren LJ, Giltay EJ, Saad F. Effects of testosterone supplementation on markers of the metabolic syndrome and inflammation in hypogonadal men with the metabolic syndrome: the double-blinded placebo-controlled Moscow study. Clin Endocrinol (Oxf). 2010 Nov: 73:602-12

[67] Kenny AM, Prestwood KM, Gruman CA, Marcello KM, Raisz LG. Effects of transdermal testosterone on bone and muscle in older men with low bioavailable testosterone levels. J Gerontol A Biol Sci Med Sci. 2001 May: 56:M266-72

[68] Kenny AM, Fabregas G, Song C, Biskup B, Bellantonio S. Effects of testosterone on behavior, depression, and cognitive function in older men with mild cognitive loss. J Gerontol A Biol Sci Med Sci. 2004 Jan: 59:75-8

[69] Kenny AM, Kleppinger A, Annis K, et al. Effects of transdermal testosterone on bone and muscle in older men with low bioavailable testosterone levels, low bone mass, and physical frailty. J Am Geriatr Soc. 2010 Jun: 58:1134-43

[70] Malkin CJ, Pugh PJ, West JN, van Beek EJ, Jones TH, Channer KS. Testosterone therapy in men with moderate severity heart failure: a double-blind randomized placebo controlled trial. Eur Heart J. 2006 Jan: 27:57-64

[71] Marks LS, Mazer NA, Mostaghel EA, et al. Effect of Testosterone Replacement Therapy on Prostate Tissue in Men With Late-Onset Hypogonadism A Randomized Controlled Tria. JAMA. 2006: 296:2351-61

[72] Nair KS, Rizza RA, O'Brien P, et al. DHEA in Elderly Women and DHEA or Testosterone in Elderly Men. N Engl J Med. 2006: 355:1647-59

[73] Park NC, Yan BQ, Chung JM, Lee KM. Oral testosterone undecanoate (AndriolÒ) supplement therapy improves the quality of life for men with testosterone deficiency. The Aging male. 2003: 6:86-93

[74] Sih R, Morley JE, Kaiser FE, Perry HM, 3rd, Patrick P, Ross C. Testosterone replacement in older hypogonadal men: a 12-month randomized controlled trial. J Clin Endocrinol Metab. 1997 Jun: 82:1661-7

[75] Snyder PJ, Peachey $\mathrm{H}$, Hannoush $\mathrm{P}$, et al. Effect of testosterone treatment on bone mineral density in men over 65 years of age. J Clin Endocrinol Metab. 1999 Jun: 84:1966-72

[76] Srinivas-Shankar U, Roberts SA, Connolly MJ, et al. Effects of testosterone on muscle strength, physical function, body composition, and quality of life in intermediate-frail and frail elderly men: a randomized, double-blind, placebo-controlled study. J Clin Endocrinol Metab. 2010 Feb: 95:639-50

[77] Steidle C, Schwartz S, Jacoby K, et al. AA2500 testosterone gel normalizes androgen levels in aging males with improvements in body composition and sexual function. J Clin Endocrinol Metab. 2003 Jun: 88:2673-81

[78] Wittert GA, Chapman IM, Haren MT, Mackintosh S, Coates P, Morley JE. Oral testosterone supplementation increases muscle and decreases fat mass in healthy elderly males with low-normal gonadal status. J Gerontol A Biol Sci Med Sci. 2003 Jul: 58:618-25 


\section{Legends to Figures}

Figure 1: Serum testosterone and risk of prostate cancer (Dose-response meta-analysis)

Figure 2: Testosterone Replacement Therapy (all forms) and absolute difference in PSA levels.

Figure 3: Testosterone Replacement Therapy risk of prostate cancer 
Table 1. Description of studies included in the endogenous testosterone levels and prostate cancer analysis

\begin{tabular}{|c|c|c|c|c|c|c|c|}
\hline Author, year (acronym) [reference] & Country & Design & Cases & Non-cases & Age & $\begin{array}{l}\text { Baseline } \\
\text { Testosterone } \\
\text { (nmol/L) }\end{array}$ & $\begin{array}{l}\text { Follow- } \\
\text { up } \\
\text { (years) }\end{array}$ \\
\hline Barrett-Connor, 1990 (RBS) [37] & USA & Cohort & 57 & 944 & 63 & 18.0 & 14 \\
\hline Chen, 2003 (CARET) [38] & USA & NCC & 300 & 300 & 61 & 14.8 & 3 \\
\hline Daniels, 2010 (OFM) [39] & USA & Cohort & 275 & 1750 & 73 & 14.3 & 4.7 \\
\hline Dorgan, 1998 (ATBC) [40] & Finland & NCC & 116 & 228 & 61 & 20.3 & 4.1 \\
\hline Gann, 1996 (PHS) [41] & USA & NCC & 222 & 390 & 62 & 16.4 & 6.3 \\
\hline Gill, 2010 (MEC) [42] & USA & NCC & 452 & 936 & 69 & 18.9 & 1.9 \\
\hline Heikkila, 1999 (FMC) [43] & Finland & $\mathrm{NCC}$ & 166 & 300 & 58 & 25.1 & 24 \\
\hline Hsing, 1993 (CLUE I) [44] & USA & NCC & 98 & 98 & 65 & 15.5 & 13 \\
\hline Muller, 2012 (REDUCE) [45] & USA & Placebo arm of RCT & 679 & 2576 & 63 & 15.8 & 4 \\
\hline Nomura, 1996 (JHCS) [46] & USA & NCC & 141 & 141 & 62 & 18.7 & 22 \\
\hline Ozasa, 2004 (JACC) [47] & Japan & NCC & 40 & 101 & 69 & 15.8 & 10 \\
\hline Parsons, 2005 (BLSA) [48] & USA & Cohort & 88 & 706 & 52 & 16.0 & 18.5 \\
\hline Platz, 2005 (HPFS) [49] & USA & NCC & 448 & 448 & 65 & 16.8 & 5 \\
\hline Severi, 2006 (MCCS) [50] & Australia & Case-cohort & 518 & 1859 & 55 & 15.7 & 8.7 \\
\hline Stattin, 2004 (NBSBWG/HHS) [32] & Finland & $\mathrm{NCC}$ & 84 & 291 & 51 & 20.7 & 10.8 \\
\hline Stattin, 2004 (NBSBWG/NSHDC) [32] & Sweden & NCC & 86 & 337 & 59 & 30.7 & 3.5 \\
\hline Stattin, 2004 (NBSBWG/Janus) [32] & Norway & $\mathrm{NCC}$ & 534 & 1599 & 47 & 23.6 & 16.7 \\
\hline Travis, 2007 (EPIC) [51] & Europe & NCC & 533 & 533 & 61 & 15.7 & 3.4 \\
\hline Vatten, 1997 (Janus)[33] & Norway & NCC & 59 & 180 & 59 & 19.9 & 10 \\
\hline Weiss, 2008 (PLCO) [52] & USA & NCC & 727 & 887 & 66 & 17.2 & 13 \\
\hline
\end{tabular}

EPIC: European Prospective Investigation into Cancer and Nutrition; FMC: Finnish Mobile Clinic Health Examination Survey; HHS: Helsinki Heart Study; NBSBWG: Nordic Biological Specimen Biobank Working Group; HPFS: Health Professionals Follow-up Study; JACC: Japan Collaborative Cohort Study; Janus: Janus Serum Bank; JHCS: Japan - Hawaii Cancer Study; MCCS: Melbourne Collaborative Cohort Study; MEC: Multiethnic cohort; NSHDC: Northern Sweden Health and Disease Cohort; OFM: Osteoporotic fractures in men; PHS: Physicians' Health Study; PLCO: Prostate, Lung, Colorectal and Ovarian cancer screening trial; RBS: Rancho Bernardo Study; REDUCE: Reduction by Dutastenide of Prostate cancer events trial 
Table 2. PSA and prostate cancer outcomes in trials of testosterone replacement therapy included in meta-analysis

\begin{tabular}{|c|c|c|c|c|c|c|c|c|}
\hline Study & Mode & $\begin{array}{l}\text { Duration } \\
\text { (days) }\end{array}$ & $\begin{array}{c}\text { Subjects } \\
\text { (Intervention) }\end{array}$ & $\begin{array}{l}\text { Subjects } \\
\text { (Control) }\end{array}$ & Country & Study population & $\begin{array}{c}\mathrm{Ag} \\
\mathrm{e}\end{array}$ & $\begin{array}{l}\text { Baseline testosterone } \\
\text { (nmol/L) }\end{array}$ \\
\hline Amory, 2004 [53] & $\mathrm{IM}$ & 1095 & 24 & 24 & USA & Healthy & 71 & 10.2 \\
\hline Aversa, 2010 [54] & IM & 365 & 40 & 10 & Italy & MS/T2DM & 58 & 8.5 \\
\hline Basaria, 2010 [55] & TD & 180 & 106 & 103 & USA & Limitations in mobility & 74 & 8.4 \\
\hline Behre, 2012 [56] & TD & 180 & 183 & 179 & Europe & Healthy & 62 & 10.5 \\
\hline Bhasin, 1998 [57] & TD & 84 & 20 & 21 & USA & HIV infected & 39 & 8.1 \\
\hline Caminiti, 2009 [58] & IM & 84 & 35 & 35 & Italy & $\mathrm{CHF}$ & 71 & 7.6 \\
\hline Chiang, 2009 [59] & TD & 90 & 20 & $\begin{array}{l}20 \\
110\end{array}$ & $\begin{array}{l}\text { Taiwan } \\
\text { The }\end{array}$ & Healthy & $\begin{array}{l}47 . \\
5^{*}\end{array}$ & 0.6 \\
\hline $\begin{array}{l}\text { Emmelot-Vonk, } 2008 \\
\text { [60] }\end{array}$ & oral & 180 & 113 & & $\begin{array}{l}\text { Netherlan } \\
\text { ds }\end{array}$ & Healthy & 67 & 10.7 \\
\hline Ferrando, 2002 [61] & $\mathrm{IM}$ & 180 & 7 & 5 & USA & Healthy & 68 & 12.6 \\
\hline Hackett, 2013 [62] & $\mathrm{IM}$ & 210 & 92 & 98 & UK & T2DM & 61 & 9.1 \\
\hline Hildreth, 2013 [63] & TD & 365 & 111 & 56 & USA & Healthy & 67 & 10.3 \\
\hline $\begin{array}{l}\text { Holmäng, } 1993 \text { [64] } \\
\text { Jones, } 2011 \text { [65] }\end{array}$ & $\begin{array}{l}\text { Oral } \\
\text { TD }\end{array}$ & $\begin{array}{l}240 \\
365\end{array}$ & $\begin{array}{c}11 \\
108\end{array}$ & $\begin{array}{c}12 \\
112\end{array}$ & $\begin{array}{l}\text { Sweden } \\
\text { Europe }\end{array}$ & $\begin{array}{l}\text { Healthy } \\
\text { MS/T2DM }\end{array}$ & $\begin{array}{l}52 \\
60\end{array}$ & $\begin{array}{c}16.4 \\
9.4\end{array}$ \\
\hline $\begin{array}{l}\text { Kalinchenko, } 2010 \\
\text { [66] } \\
\text { Kaufman, } 2011 \text { [35] }\end{array}$ & $\begin{array}{l}\text { IM } \\
\text { TD }\end{array}$ & $\begin{array}{l}210 \\
182\end{array}$ & $\begin{array}{l}113 \\
234\end{array}$ & $\begin{array}{l}71 \\
40\end{array}$ & $\begin{array}{l}\text { Russia } \\
\text { USA }\end{array}$ & $\begin{array}{l}\text { MS } \\
\text { Healthy }\end{array}$ & $\begin{array}{l}52 \\
54\end{array}$ & $\begin{array}{c}7.0 \\
10.0\end{array}$ \\
\hline Kenny, 2001 [67] & TD & 365 & 34 & 33 & USA & Healthy & 76 & 13.5 \\
\hline Kenny, 2004 [68] & $\mathrm{IM}$ & 84 & 6 & 5 & USA & Early cognitive decline & 80 & 14.1 \\
\hline Kenny, 2010 [69] & TD & 365 & 53 & 46 & USA & Osteoporosis/frailty & 77 & 13.8 \\
\hline Malkin, 2006 [70] & TD & 365 & 37 & 39 & UK & $\mathrm{CHF}$ & 64 & 13.0 \\
\hline Marks, 2006 [71] & $\mathrm{IM}$ & 180 & 22 & 22 & USA & Healthy & 69 & 8.2 \\
\hline $\begin{array}{c}\text { Morgentaler, } 2014 \\
{[34]}\end{array}$ & TD & 182 & 234 & 40 & USA & Healthy & 54 & 8.5 \\
\hline Nair, 2006 [72] & TD & 730 & 30 & 32 & USA & Healthy & 67 & 13.2 \\
\hline Park, 2003 [73] & Oral & 90 & 33 & 6 & $\begin{array}{l}\text { South } \\
\text { Korea }\end{array}$ & Healthy & NR & 9.2 \\
\hline Sih, 1997 [74] & $\mathrm{IM}$ & 365 & 17 & 15 & USA & Healthy & 68 & 9.2 \\
\hline
\end{tabular}




\begin{tabular}{|c|c|c|c|c|c|c|c|c|}
\hline Snyder, 1999 [75] & TD & 1095 & 54 & 54 & USA & $\begin{array}{c}\text { Bone mineral density }< \\
1.26 \mathrm{~g} / \mathrm{cm}^{2}\end{array}$ & 73 & 12.8 \\
\hline $\begin{array}{l}\text { Srinivas-Shankar, } \\
2010[76]\end{array}$ & TD & 180 & 130 & 132 & UK & Frailty & 74 & 10.9 \\
\hline Steidle, 2003 [77] & TD & 90 & 307 & 99 & USA & Healthy & 58 & 8.1 \\
\hline Wittert, 2003 [78] & Oral & 365 & 39 & 37 & Australia & Healthy & 69 & 16.3 \\
\hline
\end{tabular}

TD=Transdermal (includes testosterone patches or testosterone gels); $I M=$ Intramuscular; $N R=N$ Not Reported; MS = Metabolic syndrome; T2DM = type 2 diabetes mellitus; $T$ NOS= Testosterone not otherwise specified; $T$ TU = Testosterone

undecanoate; $\mathrm{TE}=$ testosterone enanthate; $\mathrm{TC}$ = testosterone cypionate; $\mathrm{CHF}=$ chronic heart failure; $\mathrm{BPH}$ = benign prostate hypertrophy; ${ }^{*}$ range $20-75$ 


\begin{tabular}{|c|c|c|c|c|c|}
\hline \multicolumn{2}{|c|}{ Endogenous testosterone } & \multicolumn{2}{|r|}{ TRT PSA } & \multicolumn{2}{|r|}{ TRT PCA } \\
\hline $\begin{array}{c}\# \\
\text { Studies }\end{array}$ & $\begin{array}{l}\text { Summary estimate RR } \\
\text { per } 5 \mathrm{nmol} / \mathrm{L}^{* *}(95 \% \mathrm{Cl})\end{array}$ & $\begin{array}{c}\# \\
\text { Studies }\end{array}$ & $\begin{array}{c}\text { Summary estimate } \\
\text { PSA: absolute } \\
\text { difference }(\mathrm{ng} / \mathrm{mL}) \\
(95 \% \mathrm{Cl})\end{array}$ & $\begin{array}{c}\# \\
\text { Studies }\end{array}$ & $\begin{array}{c}\text { Summary estimate } \\
\text { MH-OR }(95 \% \mathrm{Cl})\end{array}$ \\
\hline
\end{tabular}

\section{Analysis}

Main analysis (all studies)

Sensitivity analysis: high vs. low serum

testosterone approach

Sensitivity analysis: studies from EHPCCG

Sensitivity analysis: include study with no SD

assuming SD = 1 [34]

Sensitivity analysis: include cases occurring

during open-label phase, or additional follow-

up, etc

$\begin{array}{ll}20 & 0.99(0.96 ; 1.02) \\ 20 & 0.98(0.88 ; 1.09) \\ 16 & 0.97(0.93 ; 1.01)\end{array}$

$(95 \% \mathrm{Cl})$

\begin{tabular}{|c|c|c|c|c|c|c|}
\hline Studies conducted in the USA & 11 & $1.01(0.98 ; 1.05)$ & 13 & $0.34(-0.41 ; 1.10)$ & 7 & $1.32(0.33 ; 5.25)$ \\
\hline Studies conducted in Europe & 7 & $0.95(0.90 ; 1.01)$ & 10 & $0.09(-0.58 ; 0.76)$ & 4 & $0.24(0.01 ; 8.77)$ \\
\hline Age at baseline $<65$ years & 15 & $0.99(0.95 ; 1.02)$ & 10 & $0.11(-0.47 ; 0.69)$ & 3 & $2.04(0.01 ; 461.7)$ \\
\hline Age at baseline $\geq 65$ years & 5 & $1.02(0.93 ; 1.11)$ & 15 & $0.30(-0.41 ; 1.00)$ & 8 & $0.74(0.22 ; 2.54)$ \\
\hline Short Follow-up * & 12 & $0.99(0.96 ; 1.03)$ & 15 & $0.07(-0.41 ; 0.55)$ & 7 & $0.58(0.14 ; 2.41)$ \\
\hline Long Follow-up * & 8 & $1.00(0.93 ; 1.09)$ & 11 & $0.17(-0.57 ; 0.91)$ & 4 & $2.15(0.12 ; 37.46)$ \\
\hline Baseline Testosterone $\leq 11 \mathrm{nmol} / \mathrm{L}$ & & & 17 & $0.07(-0.37 ; 0.51)$ & 8 & $0.75(0.22 ; 2.54)$ \\
\hline Baseline Testosterone $>11 \mathrm{nmol} / \mathrm{L}$ & & & 9 & $0.25(-0.70 ; 1.20)$ & 3 & $2.05(0.01 ; 469.8)$ \\
\hline Studies conducted in healthy subjects & & & 15 & $0.08(-0.43 ; 0.58)$ & 7 & $0.63(0.17 ; 2.39)$ \\
\hline $\begin{array}{l}\text { Studies conducted in subjects with } \\
\text { comorbidities }\end{array}$ & & & 11 & $0.14(-0.52 ; 0.81)$ & 4 & $2.98(0.07 ; 122.67)$ \\
\hline Administration: transdermal & & & 13 & $0.20(-0.41 ; 0.81)$ & 7 & $2.57(0.31 ; 21.16)$ \\
\hline Administration: intramuscular & & & 9 & $0.21(-0.56 ; 0.98)$ & 3 & $0.61(0.03 ; 11.38)$ \\
\hline Administration: oral & & & 4 & $-0.21(-1.40 ; 0.98)$ & 1 & NR \\
\hline Testosterone undecanoate & & & 8 & $-0.12(-0.78 ; 0.55)$ & 2 & NR \\
\hline Testosterone enhanthate & & & 4 & $0.61(-1.42 ; 2.63)$ & 2 & NR \\
\hline Testosterone: other and unspecified & & & 13 & $0.20(-0.41 ; 0.81)$ & 7 & $2.57(0.31 ; 21.16)$ \\
\hline
\end{tabular}

Testosterone: other and unspecified

$0.20(-0.41 ; 0.81)$

$2.57(0.31 ; 21.16)$

controlled trials; *Long Follow-up: > 10 years for cohort studies, >1yr year for randomized controlled trials; **except for the high vs. low analysis 


\section{FIGURES}

Study

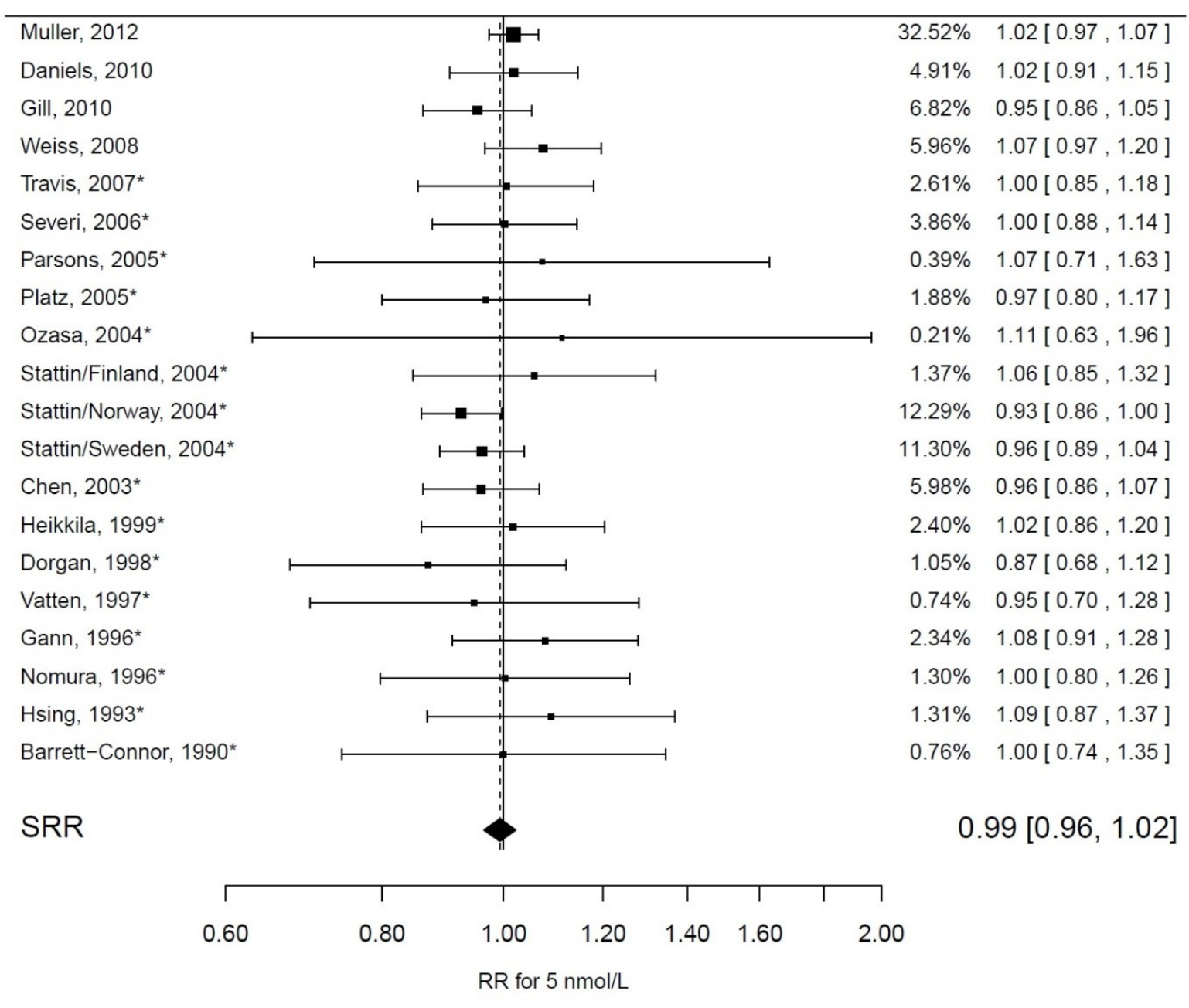

*: study included in EHPCCG pooled analysis
Weights $\quad \mathrm{RR}[95 \% \mathrm{Cl}]$

Heterogeneity: $I^{2}=0 \%[0 \% ; 19 \%] ; Q=12.20, d f=19(p=0.88)$ Publication bias: Begg $=0.16(p=0.87)$; Egger $=-0.79(p=0.17)$; Macaskill $=-0.41(p=0.69)$ 


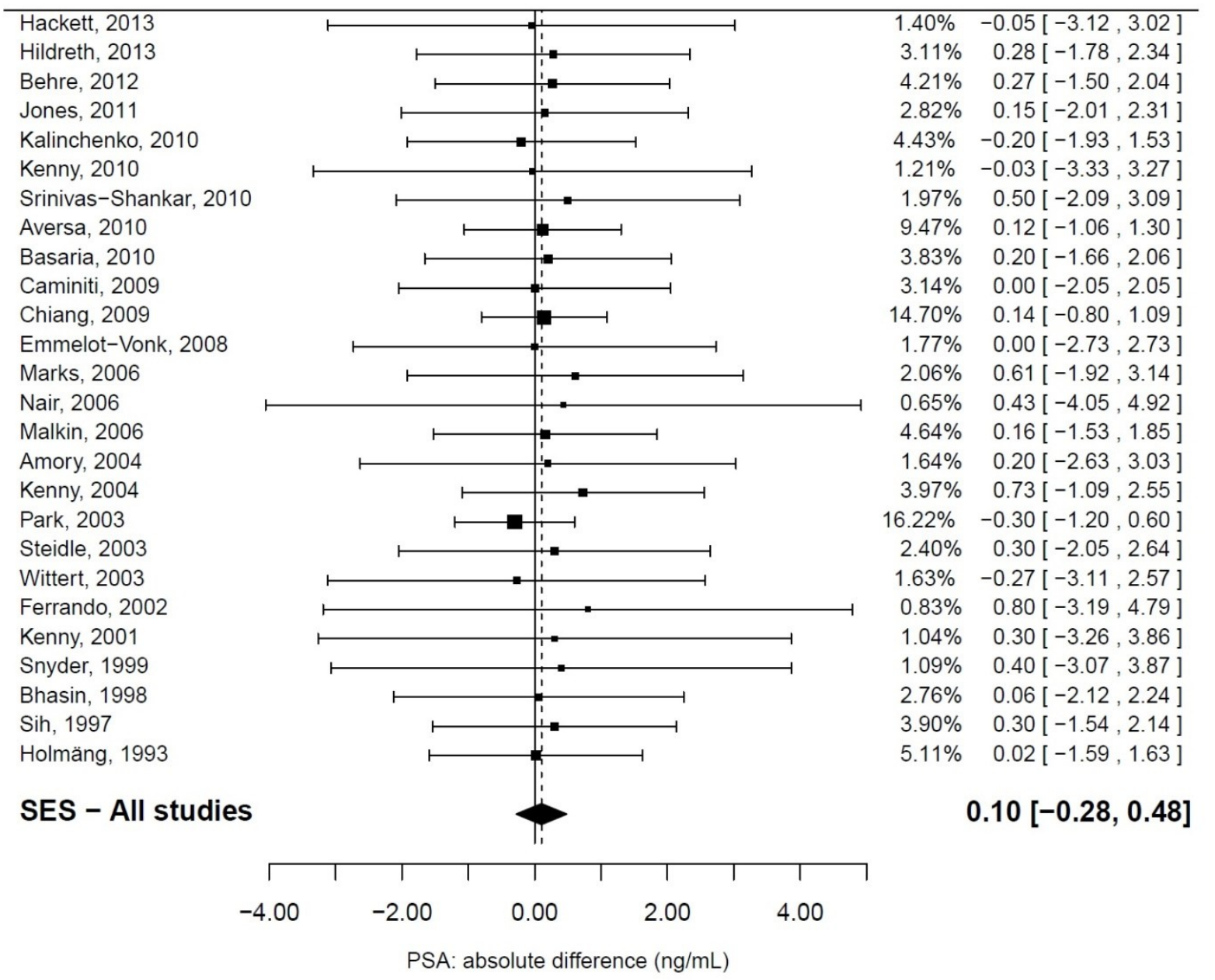




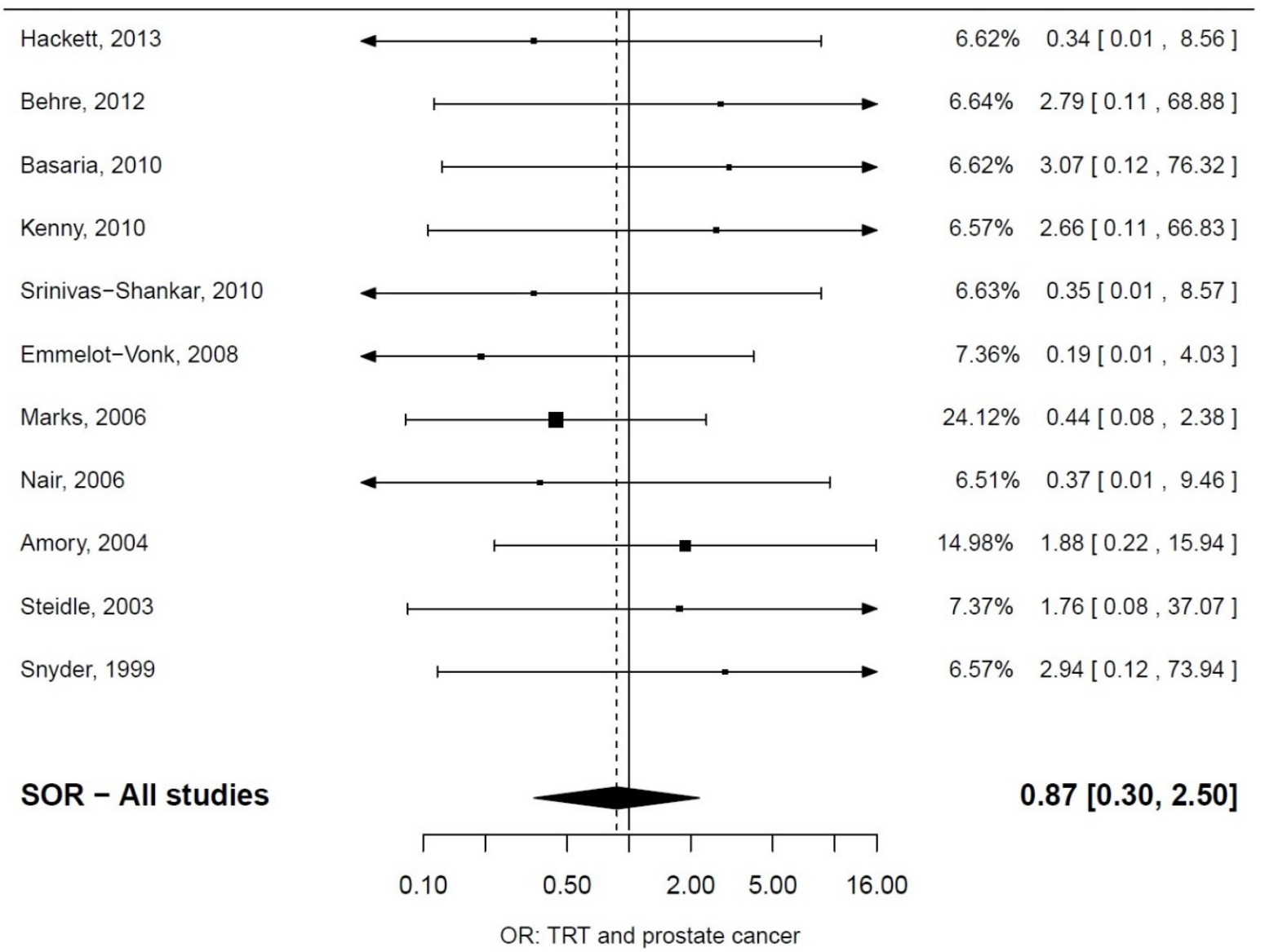

SOR: Summary odds ratio

Figure 3 


\section{Supplementary figures}

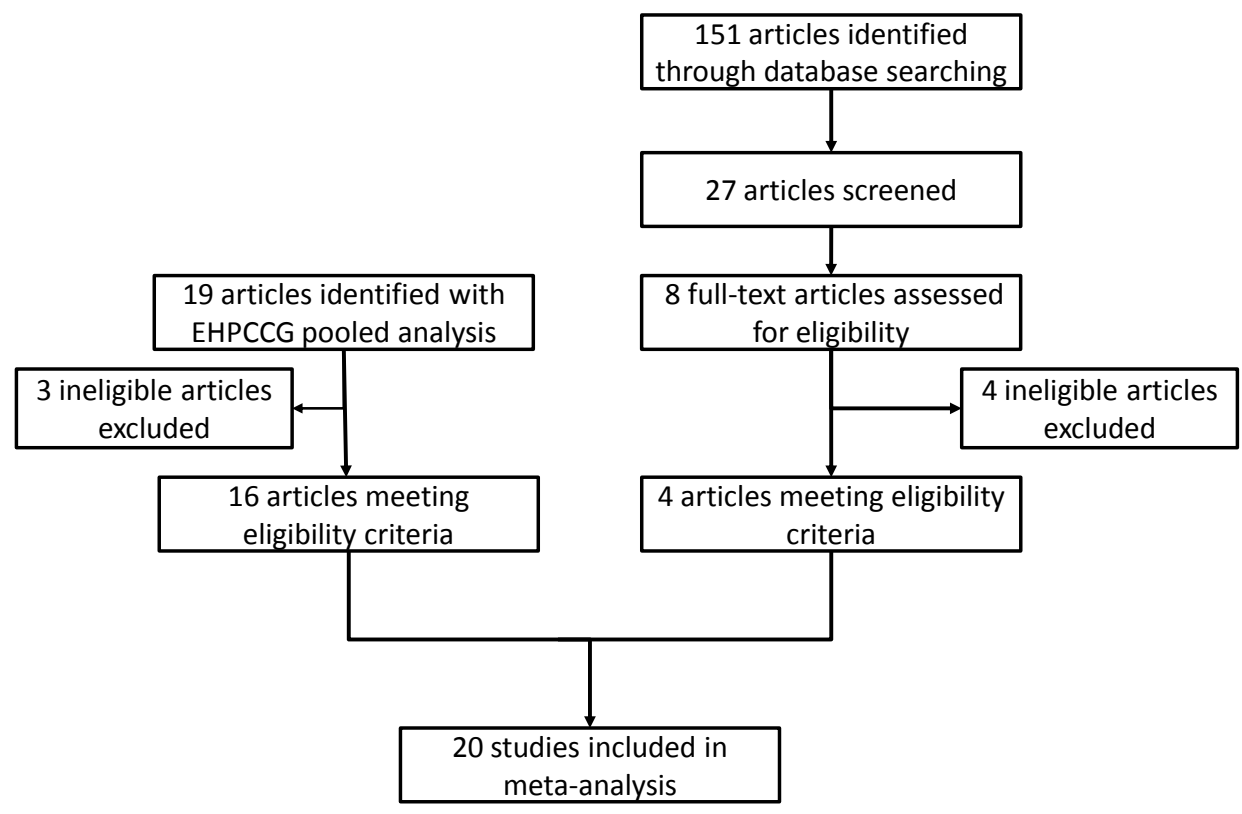

PubMed keywords: "serum testosterone", "prostate cancer", "cohort", "prospective", "randomized controlled trial"

Figure S1: Literature search flowchart for study selection: endogenous testosterone and prostate cancer

Figure 1b: PRISMA for Exogenous testosterone and prostate cancer

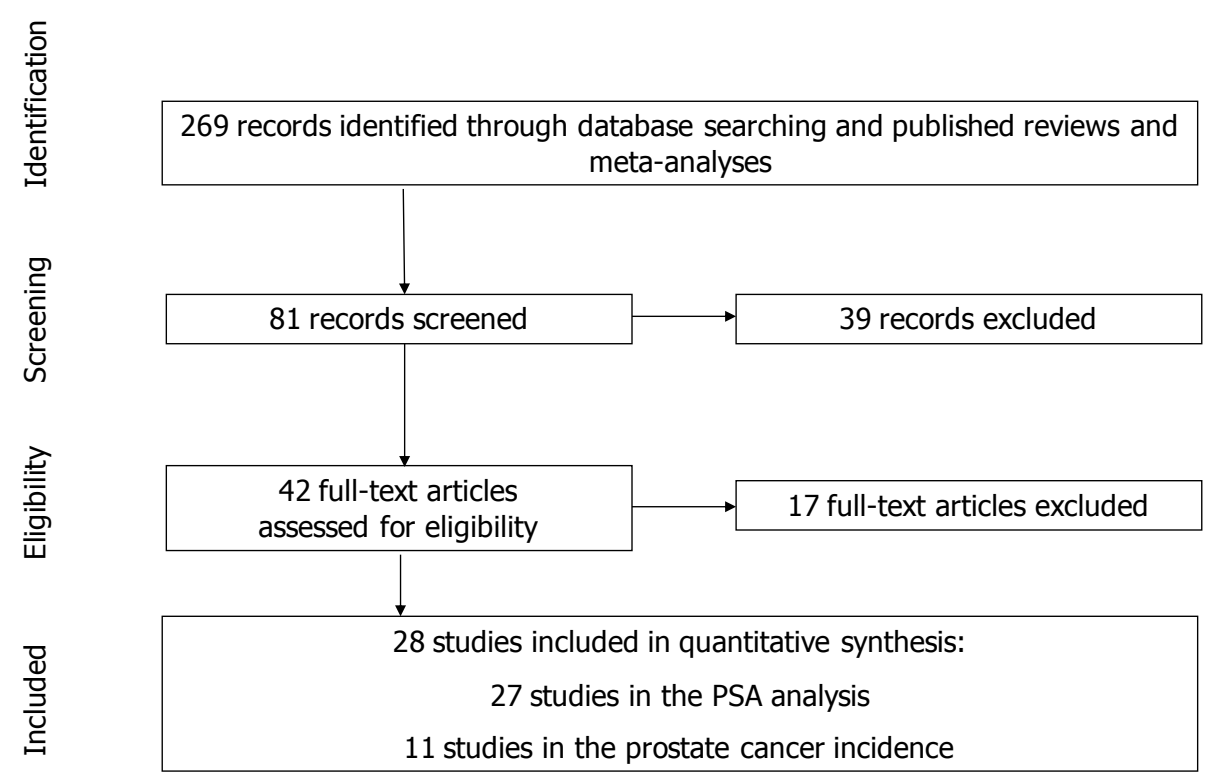

Figure S2: Literature search flowchart for study selection: Exogenous testosterone, Prostate Specific Antigen, and prostate cancer 


\section{Supplementary methods: PLCO Study}

Most studies reported only baseline (BPSA) and end of study (EPSA) PSA with corresponding standard deviations, but not the average difference $\left(\triangle_{\mathrm{PSA}}\right)$ and corresponding standard deviation. The average difference was therefore estimated as the difference of the average PSA at the end of study minus the average PSA at baseline. However, it would have been erroneous to consider the two measurements of PSA as independent in the computation of the variance of the difference and we needed to estimate the covariance between measurements. The following formula was used to compute the variance of the difference:

$$
\operatorname{Var}(\triangle P S A)=\operatorname{var}\left(B_{P S A}\right)+\operatorname{var}\left(E_{P S A}\right)-2 r \sqrt{ }\left(\operatorname{Var}\left(B_{P S A}\right) * \operatorname{var}\left(E_{P S A}\right)\right)
$$

The coefficient $r$ represents the correlation between the two measurements. It was computed from the PLCO study with dataset as of August 2012 [1].

Interpretation of changes in PSA (particularly in low ranges i.e. $\leq 4 \mathrm{ng} / \mathrm{mL}$ ) is not straightforward and PSA testing has been shown to induce substantial over-diagnosis of prostate cancer, mainly due to poor specificity of the test. To help understand the occurrence and magnitude of variations of PSA levels in men with initially low levels of PSA, a detailed analysis of subjects participating in the intervention arm of the Prostate, Lung, Colorectal and Ovarian Cancer (PLCO) Cancer Screening Trial who had an initial PSA level $\leq 4 \mathrm{ng} / \mathrm{mL}$ was conducted.

Data were abstracted from the PLCO study [1] on all men in the intervention arm with two tests performed in a period of less than two years and with an initial result of the first test $\leq 4 \mathrm{ng} / \mathrm{mL}$. The range of variation of the second test compared to initial level was examined.

Among the 38,340 men participating to the intervention arm, 31,286 men had two PSA tests performed within two years and with an initial value $\leq 4 \mathrm{ng} / \mathrm{mL}$. From these data, a correlation coefficient $r$ of 0.64 was estimated and used in our analysis.

\section{Reference}

[1] Andriole GL, Crawford ED, Grubb RL, 3rd, et al. Prostate cancer screening in the randomized Prostate, Lung, Colorectal, and Ovarian Cancer Screening Trial: mortality results after 13 years of follow-up. J Natl Cancer Inst. 2012 Jan 18: 104:125-32 